\title{
Water activity and activation diameters from hygroscopicity data - Part II: Application to organic species
}

\author{
K. A. Koehler ${ }^{1}$, S. M. Kreidenweis ${ }^{1}$, P. J. DeMott ${ }^{1}$, A. J. Prenni ${ }^{1}$, C. M. Carrico ${ }^{1}$, B. Ervens ${ }^{1}$, and G. Feingold ${ }^{2}$ \\ ${ }^{1}$ Department of Atmospheric Science, Colorado State University, Fort Collins, CO, 80523, USA \\ ${ }^{2}$ NOAA, Earth System Research Laboratory, Boulder, Colorado 80305, USA
}

Received: 26 September 2005 - Published in Atmos. Chem. Phys. Discuss.: 28 October 2005

Revised: 25 January 2006 - Accepted: 25 January 2006 - Published: 10 March 2006

\begin{abstract}
A method has been developed for using particle hygroscopicity measurements made with a humidified tandem differential mobility analyzer (HTDMA) to determine water activity as a function of solute weight percent. In Part I, the method was tested for particles composed of sodium chloride and ammonium sulfate. Here, we report results for several atmospherically-relevant organic species: glutaric acid, malonic acid, oxalic acid and levoglucosan. Predicted water activities for aqueous dicarboxylic acid solutions are quite similar in some cases to published estimates and the simplified predictions of Köhler theory, while in other cases substantial differences are found, which we attribute primarily to the semivolatile nature of these compounds that makes them difficult to study with the HTDMA. In contrast, estimates of water activity for levoglucosan solutions compare very well with recently-reported measurements and with published data for aqueous glucose and fructose solutions. For all studied species, the critical dry diameters active at supersaturations between 0.2 and $1 \%$ that are computed with the HTDMA-derived water activities are generally within the experimental error $(\sim 20 \%)$ estimated in previously-published direct measurements using cloud condensation nuclei counters. For individual compounds, the variations in reported solution water activity lead to uncertainties in critical dry diameters of 5-25\%, not significantly larger than the uncertainty in the direct measurements. To explore the impact of these uncertainties on modeled aerosolcloud interactions, we incorporate the variations in estimates of solution water activities into the description of hygroscopic growth of aerosol particles in an adiabatic parcel model and examine the impact on the predicted drop number concentrations. For the limited set of initial conditions examined here, we find that the uncertainties in critical dry diameters for individual species lead to $0-21 \%$ changes in drop
\end{abstract}

Correspondence to: $\mathrm{K}$. A. Koehler

(kkoehler@lamar.colostate.edu) number concentration, with the largest effects at high aerosol number concentrations and slow updraft velocities. Ammonium sulfate, malonic acid and glutaric acid have similar activation behavior, while glutaric acid and levoglucosan are somewhat less hygroscopic and lead to lower drop number concentrations; sodium chloride is the most easily activated compound. We explain these behaviors in terms of a parameter that represents compound hygroscopicity, and conclude that this parameter must vary by more than a factor of 2 to induce more than a $15 \%$ change in activated drop number concentrations. In agreement with earlier studies, our results suggest that the number concentration of activated drops is more sensitive to changes in the input aerosol size and number concentrations and the applied updraft velocity than to modest changes in the aerosol composition and hygroscopic properties.

\section{Introduction}

The earliest reported experimental investigations of the activity of various components of the atmospheric aerosol as cloud condensation nuclei $(\mathrm{CCN})$ focused primarily on inorganic salts such as ammonium sulfate and sodium chloride, compounds considered dominant components of CCN, particularly in marine environments or in areas heavily influenced by $\mathrm{SO}_{2}$ sources. However, organics have been shown to be a considerable fraction of the aerosol mass (Saxena et al., 1995) in the clean as well as polluted environments, and the presence of organic species in atmospheric aerosol can affect aerosol hygroscopicity and the ability of mixed particles to serve as CCN (Corrigan and Novakov, 1999; Giebl, 2002; Kumar et al., 2003; Prenni et al., 2003, 2001; Raymond and Pandis, 2002). Relative to inorganic aerosol components, much less is known about the hygroscopic growth and cloud-nucleating behavior of organic species in atmospheric particulate matter.

Published by Copernicus GmbH on behalf of the European Geosciences Union. 
Table 1. Chemical properties of investigated species.

\begin{tabular}{|c|c|c|c|c|c|c|c|c|}
\hline Species & $\begin{array}{l}\text { Molecular } \\
\text { Formula }\end{array}$ & $\begin{array}{c}\text { Molecular } \\
\text { Weight } \\
(\mathrm{g} / \mathrm{mol})\end{array}$ & $\begin{array}{l}\text { Density } \\
\left(\mathrm{g} / \mathrm{cm}^{3}\right)\end{array}$ & $\begin{array}{c}\text { Solubility } \\
\left(\mathrm{g} / 100 \mathrm{~cm}^{3}\right. \\
\left.\mathrm{H}_{2} \mathrm{O}\right)\end{array}$ & $\begin{array}{c}\text { Vapor } \\
\text { Pressure }^{\mathrm{c}} \\
\text { (torr) }\end{array}$ & $\begin{array}{c}\text { Solution } \\
\text { Surface } \\
\text { Tension Used } \\
\left(\mathrm{J} \mathrm{m}^{-2}\right)\end{array}$ & $\begin{array}{c}\text { Deliquescence } \\
R H\end{array}$ & $\begin{array}{c}\text { pKa and } \\
\text { associated } v \text { for a } \\
1 \text { molar solution }\end{array}$ \\
\hline glutaric acid & $\mathrm{C}_{5} \mathrm{H}_{8} \mathrm{O}_{4}$ & 132.1 & 1.42 & $\begin{array}{c}160^{\mathrm{a}} \\
(61.5 \mathrm{wt} \%)\end{array}$ & $4.1 \times 10^{-6}$ & $\begin{array}{c}5.0769 \times 10^{-3} \mathrm{z} \\
+58.414 \times 10^{-3 \mathrm{~b}}\end{array}$ & $85.2-99^{\mathrm{d}}, 89^{\mathrm{e}}$ & $\begin{array}{c}4.32 \\
\nu=1.025\end{array}$ \\
\hline malonic acid & $\mathrm{C}_{3} \mathrm{H}_{4} \mathrm{O}_{4}$ & 104.1 & 1.62 & $\begin{array}{c}76^{\mathrm{a}} \\
(43 \mathrm{wt} \%)\end{array}$ & $1.0 \times 10^{-5}$ & $\begin{array}{c}4.7018 \times 10-3 \mathrm{z} \\
+64.361 \times 10^{-3 \mathrm{~b}}\end{array}$ & $65.2-91^{\mathrm{d}}, 72^{\mathrm{e}}, 84^{\mathrm{f}}$ & $\begin{array}{c}2.85 \\
v=1.036\end{array}$ \\
\hline oxalic acid & $\mathrm{C}_{2} \mathrm{H}_{2} \mathrm{O}_{4}$ & 90 & 1.9 & $\begin{array}{c}22^{\mathrm{a}} \\
(18 \mathrm{wt} \%)\end{array}$ & $3.5 \times 10^{-5}$ & $0.072^{\mathrm{b}}$ & $93-99^{d}, 97-99^{f}$ & $\begin{array}{c}1.25 \\
\nu=1.211\end{array}$ \\
\hline $\begin{array}{l}\text { oxalic acid } \\
\text { (dihydrate) }\end{array}$ & $\begin{array}{c}\mathrm{C}_{2} \mathrm{H}_{2} \mathrm{O}_{4} \\
\cdot 2 \mathrm{H}_{2} \mathrm{O}\end{array}$ & 126 & 1.65 & & no data & 0.072 & & \\
\hline levoglucosan & $\mathrm{C}_{6} \mathrm{H}_{10} \mathrm{O}_{5}$ & 162.1 & 1.64 & & non-volatile & $0.073^{\mathrm{h}}$ & $80^{\mathrm{i}}$ & \\
\hline glucose & $\mathrm{C}_{6} \mathrm{H}_{12} \mathrm{O}_{6}$ & 180.1 & 1.562 & $\begin{array}{c}90.9^{g} \\
(47.6 \mathrm{wt} \%)\end{array}$ & non-volatile & 0.072 & $90^{\mathrm{i}}$ & $\begin{array}{c}12.46^{\mathrm{a}} \\
\nu=1.000\end{array}$ \\
\hline fructose & $\mathrm{C}_{6} \mathrm{H}_{12} \mathrm{O}_{6}$ & 180.1 & 1.6 & Very soluble ${ }^{\mathrm{g}}$ & non-volatile & 0.072 & & $\begin{array}{c}12.27^{\mathrm{a}} \\
\nu=1.000\end{array}$ \\
\hline
\end{tabular}

$\mathrm{z}=\ln$ (molarity);

${ }^{a}$ based CRC Handbook of Physical Properties of Organic Chemicals at 298 K;

${ }^{\mathrm{b}}$ based on Shulman et al. (1996) as reported in Ervens et al. (2004);

${ }^{\mathrm{c}}$ from Prenni et al. (2001);

d Compiled from Wise et al. (2003) at 293-299 K;

e from Parsons et al. (2004) at $298 \mathrm{~K}$;

${ }^{\mathrm{f}}$ from Braban et al. (2003) T=264-298 K;

$\mathrm{g}$ from Mallinckrodt Chemicals Material Data Safety Sheet;

h Tuckermann and Cammenga (2004) at $293 \mathrm{~K}$;

${ }^{\mathrm{i}}$ Mochida and Kawamura (2004) at $293 \mathrm{~K}$;

In Part I (Kreidenweis et al., 2005), we proposed a methodology using water uptake data for particles below water saturation to calculate solution water activity as a function of solute weight percent (wt \%). Hygroscopicity data were obtained using a humidified tandem differential mobility analyzer (HTDMA) and the methodology was applied to measurements for sodium chloride and ammonium sulfate solutions. The water activities were then used to predict $\mathrm{CCN}$ activation diameters of sodium chloride and ammonium sulfate particles, and results were compared with available experimental measurements. Here, the methodology is applied to several atmospherically-relevant organic species. Glutaric acid, malonic acid and oxalic acid are low molecular weight dicarboxylic acids, and are important components of the identified fraction of organic mass in the urban atmosphere and even in the remote atmosphere of the Arctic (Kawamura et al., 1996). They are produced in automobile exhaust and through reactions in photochemical smog. They are water soluble and have sufficiently low vapor pressures that they are expected to partition into the particulate phase (Makar, 2001).

Wood smoke often accounts for $20-30 \%$ of the ambient fine-particle mass concentrations in the atmosphere (Fine et al., 2002); it is formed primarily from biomass burning, forest fires and residential wood burning for heating. Levoglu$\operatorname{cosan}(1,6$-anhydro- $\beta$-D-glucopyranose) is a commonly used tracer for wood smoke found in the fine (diameter $<2.5 \mu \mathrm{m}$ ) particle fraction. Of the particulate mass produced by residential wood burning, 9-16\% is levoglucosan, and thus it can be a significant portion of the organic aerosol mass (Fine et al., 2002). Levoglucosan is believed to be a good tracer because it does not decay in sunlight (over $8 \mathrm{~h}$ ) and is emitted at high enough concentrations that it can be detected substantial distances from the original source (Simoneit et al., 1999). Levoglucosan is structurally similar to the sugars glucose and fructose, differing only by one water molecule. Properties of the studied species are listed in Table 1.

\section{Measurements of water uptake}

The HTDMA system used in this work to measure the water uptake is described in Part I. Briefly, aerosol was generated via atomization from a $1 \mathrm{wt} \%$ aqueous organic solution in ultrapure water. The particles are dried to a relative humidity less than $5 \%$ and growth experiments performed on dry, nearly-monodisperse $100 \mathrm{~nm}$ particles selected by a differential mobility analyzer (DMA1) with a sheath to sample ratio of 10:1. The dry particles are exposed to controlled relative humidity in the HTDMA conditioning section, which is a Permapure (model MD-110-48S, PermaPure, Inc.) membrane tube; sample flows through the inner tube, 
while controlled-RH air makes up the outer sheath air flow. The relative humidity $(R H)$ setpoint is maintained through a second DMA (DMA2), which measures the diameter of the conditioned particle. The total residence time in the HTDMA is approximately $5 \mathrm{~s}$. The growth factor $(G F)$ is defined as

$G F=\frac{D_{\text {wet }}(R H)}{D_{\text {dry }}}$,

where $D_{\text {wet }}$ is the particle diameter measured in DMA2 at relative humidity $R H$ and $D_{\text {dry }}$ is the dry size of the particle selected by DMA1. Sufficient observations are made to define the variation in $G F$ with $R H$ over a wide range, generally $40 \%<R H<95 \%$. We estimate the uncertainty in $G F$ to be \pm 0.02 at the $95 \%$ confidence level and the relative humidity sensors are accurate within $\pm 2 \%$ over the range studied (Carrico et al., 2005).

It is well-known that the hygroscopic behavior of most dry inorganic salts will undergo a deliquescence transition when exposed to increasing $R H$, corresponding to formation of the saturated solution. At humidities below the deliquescence point, these crystalline particles do not take up any water; rather deliquescence occurs when the ambient $R H$ is approximately equal to the water activity of the saturated solution. Expected deliquescence point ranges for the organic species studied here vary greatly and are shown in Table 1 . Several prior experimental studies of the hygroscopic growth of these species, however, did not observe deliquescence, but rather reported a continuous uptake of water from low $R H$ with increasing $R H$ (e.g. Prenni et al., 2001). The water uptake data for the dicarboxylic acids, as previously reported by Prenni et al. (2001), as well as measurements made in our laboratory for ammonium sulfate, sodium chloride and levoglucosan particles, are shown in Fig. 1. Although deliquescence behavior was observed for the inorganic salts, continuous water uptake was observed for the organic species. While some species may take up small amounts of water through an adsorption mechanism (Mikhailov et al., 2004), it is more likely that the observed behavior is due to insufficient drying of the atomized particles, yielding metastable, highly-concentrated solutions at low $R H$ that take up additional water as $R H$ is increased (Braban et al., 2003). This adds some uncertainty to the growth factors because part of the assumed dry volume is occupied by water and not solute. As demonstrated in the error analysis in Part I (Kreidenweis et al., 2005), an error of $0.02 \mathrm{~nm}$ in the dry sizes, propagated through our extrapolation to high $R H$, leads to a $\sim 2 \%$ error in the predicted critical $\mathrm{CCN}$ acitvation diameter.

During HTDMA experiments, evaporation, further drying of an initially metastable solution, and/or rearrangement (Mikhailov et al., 2004) was a problem for some of the organic species. These phenomena are possible explanations for the following observation. When particles were selected from a dried sample stream $(R H<5 \%)$ at DMA1 and maintained at dry conditions during transit to DMA2, the diameter detected at DMA2 was significantly smaller than that

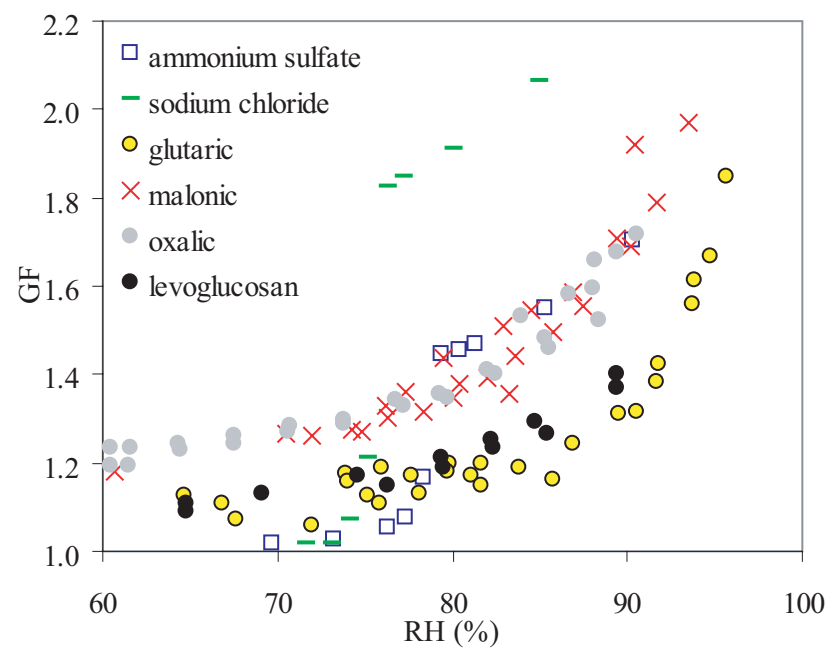

Fig. 1. Hygroscopic growth factors for $100 \mathrm{~nm}$ particles composed of the studied species $(\mathrm{T}=303 \mathrm{~K})$. Data for the dicarboxylic acids are from the work of Prenni et al. (2001). The oxalic acid data have been corrected for bound water mass (see Sect. 4.1.1).

selected in DMA1, whereas it was expected to be unchanged. Ratioing the measured DMA2 and DMA1 diameters yields a $G F<1$ at low $R H$. The semivolatile nature of the dicarboxylic acids (Table 1) suggests that they could evaporate when exposed to scrubbed and dried sheath air in the HTDMA conditioning system, as reported by Prenni et al. (2001) and others (e.g. Bilde et al., 2003). If an initially metastable solution particle is chosen in DMA1, the additional drying time provided by the conditioning system may initiate complete drying, with the loss of water mass recorded as a reduction in diameter by DMA2. Finally, if the initial dry particle has an irregular shape that results in a drag force larger than that for a spherical particle, the apparent diameter selected in DMA1 will be larger than the true volume equivalent diameter. If small amounts of water are then adsorbed in the conditioning system at low RH, and the particle becomes spherical without substantially changing its total volume, this change in shape will be manifested in the DMA2 measurements as an apparent reduction in size from the initial dry diameter (Mikhailov et al., 2004).

We apply the same equations and assumptions reported in Bilde et al. (2003) to compute particle size changes due to evaporation. Using the vapor pressure estimates in Table 1, assuming that the gas-phase concentration of the organic species away from the surface of the drop remains zero, and assuming that the temperature of the organic particle remains at $303 \mathrm{~K}$, which gives the maximum evaporation, we found that the calculated change in particle size due to evaporation was comparable to that observed. For a $5 \mathrm{~s}$ residence time, the predicted reduction in particle diameter is about $20 \mathrm{~nm}$ for an initially $100 \mathrm{~nm}$ malonic acid particle, similar to our observations. Applying the vapor pressures reported 


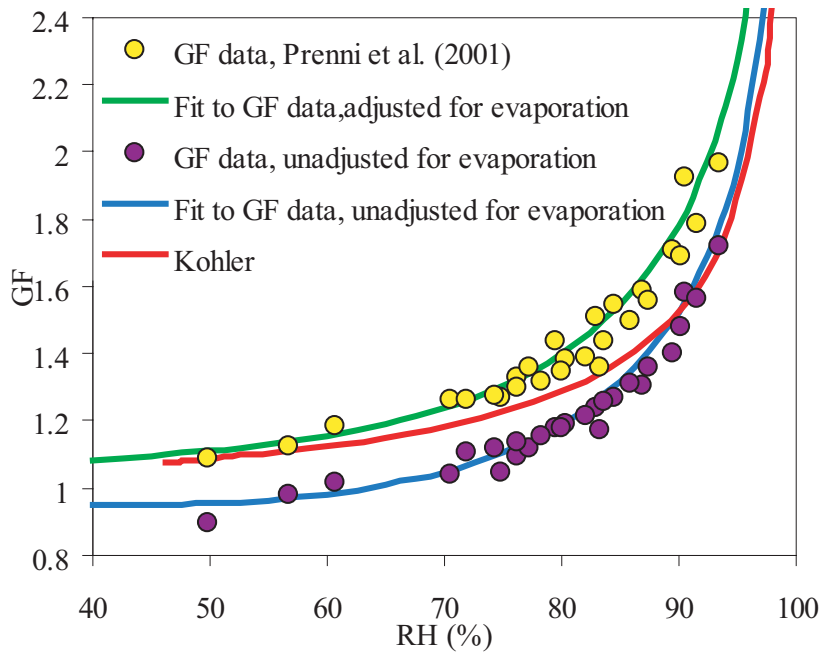

Fig. 2. Growth factors for $100 \mathrm{~nm}$ malonic acid particles with and without evaporation adjustment and the corresponding fits, as compared to Köhler theory with $\nu=1$.

by Bilde et al. (2003) resulted in calculated size changes within $5 \mathrm{~nm}$ of the predictions using the values in Table 1. While some studies have found significant shrinking due to restructuring can occur (Jimenez et al., 2003), we find it unlikely that the initial particle shape can contribute to such a large apparent change in size in this case. A shape factor of 1.2 would be required to match the observations. Since we observe continuous water uptake, we expect these particles to be highly concentrated droplets, and thus very close to spherical. We therefore conclude that evaporation is the most probable cause of the particle shrinking.

All of the HTDMA data reported in this work, unless otherwise noted, have been adjusted to account for the apparent loss of solute mass. It was assumed that the initial dry size of the particles, $D_{\text {dry }}$, selected by DMA 1 , nominally $100 \mathrm{~nm}$, was equal to the size measured by DMA2 at $\mathrm{RH}<5 \%$ (Prenni et al., 2001). Figure 2 shows the change in the $G F$ for malonic acid when this adjustment is considered and neglected. For the dicarboxylic acids, if the observed reduction in size is in fact due to evaporation of the semivolatile organic, the applied constant adjustment may be too large for data at higher $R H$. As the $R H$ in the instrument is increased, the evaporation of the organic species in the conditioner will be suppressed since the vapor pressure over the solution will decrease with increasing $R H$. Although the corrected $G F$ s will constitute our standard case, we will show selected results neglecting this adjustment to indicate its effect on our results and conclusions. GFs predicted by Köhler theory show the necessity of the evaporation adjustment at low $R H$, yet merge toward the $G F$ s without evaporation adjustment at higher $R H$.

Figure 3 shows the $G F$ s for levoglucosan measured in this work, compared to the GFs measured by Mochida and Kawamura (2004) and those measured and fit by Chan et

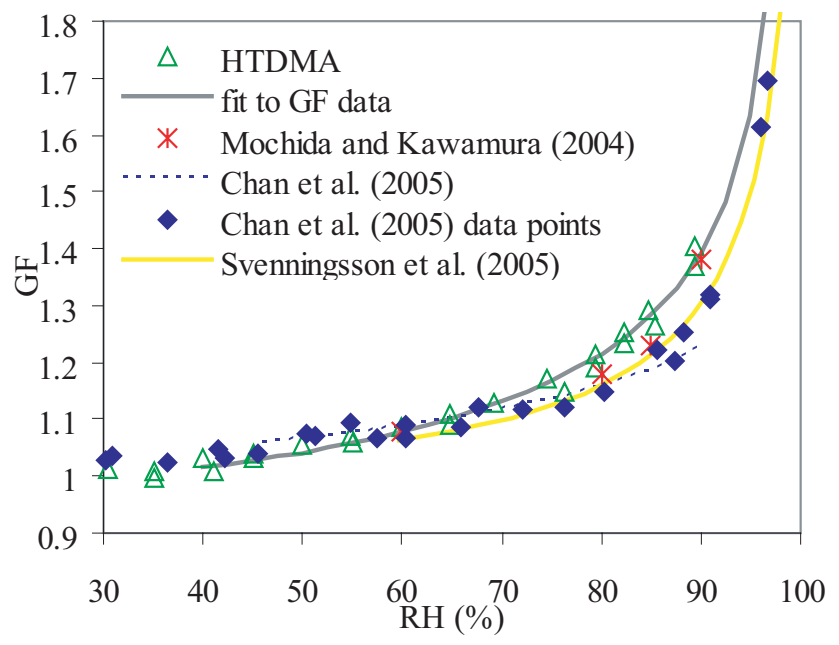

Fig. 3. Hygroscopic growth factors for $100 \mathrm{~nm}$ levoglucosan particles $(\mathrm{T}=303 \mathrm{~K})$ as compared to growth factors found by Mochida and Kawamura (2004) for $100 \mathrm{~nm}$ particles $(\mathrm{T}=298 \mathrm{~K})$, Chan et al. (2005) fit ( $\mathrm{T}=298 \mathrm{~K})$, Chan et al. (2005) data points including the converted data from bulk solutions, and Svenningsson et al. (2005) fit. In the Chan et al. (2005) and Svenningsson et al. (2005) trends, $a_{w}$ has been converted to $R H$ using Eq. (2) for $100 \mathrm{~nm}$ dry particles. The fit of Eq. (6) to the HTDMA data is also shown.

al. (2005). The fit reported by Chan et al. (2005) does not include their measurements of water activity in a bulk solution, which we have included separately in Fig. 3, and therefore should not be extrapolated above $R H=90 \%$ (C. Chan, personal communication). Using Eq. (2) (see below), we have converted the water activity fits provided by Chan et al. (2005) and their water activity data points to $R H$ by accounting for the Kelvin effect over a solution drop formed on a $100 \mathrm{~nm}$ dry particle. Figure 3 also includes the fit of $G F$ measurements in terms of water activity of levoglucosan reported by Svenningsson et al. (2005), again with $a_{w}$ converted to $R H$ by Eq. (2). All of the $G F$ estimates shown in Fig. 3 are in reasonably good agreement. Although Mochida and Kawamura (2004) reported an expected deliquescence $R H$ of about $80 \%$ for levoglucosan, based on measurements of the water activity of the saturated bulk solution, we did not observe a deliquescence transition in $100 \mathrm{~nm}$ particles. In their HTDMA experiments, Mochida and Kawamura (2004) and Svenningsson et al. (2005) also observed continuous water uptake from a low $R H$ and hypothesized that the levoglucosan particles were not completely dried at low $R H$.

Bilde and Svenningsson (2004) found that incomplete drying and incorporation of small amounts of inorganic salts could significantly influence the $\mathrm{CCN}$ activity of organic particles they generated in their laboratory. Even contamination with less than $1 \mathrm{wt} \% \mathrm{NaCl}$ significantly reduced the required supersaturation for nucleation of a slightly soluble organic particle. Those authors note that trace impurities in 
experiments are unavoidable and arise either from the water used to create solutions (even ultra-purified) or from the purchased organic compounds themselves. Bilde and Svenningsson (2004) also demonstrated a dramatic decrease in critical supersaturation for organic particles that, instead of being dried, were held as metastable, highly concentrated solution droplets, over the required supersaturation for activation of initially completely-dried particles. Thus the initial particle phase state can play a role in controlling the observed CCN activity.

\section{Model description}

As discussed in Part I, the condition for an aqueous solution droplet to be in equilibrium with water vapor in its environment is expressed as:

$s=a_{w} \times K e$.

where

$K e=\exp \left(\frac{4 \sigma_{\mathrm{sol}} M W_{w}}{R T \rho_{w} D_{\mathrm{wet}}}\right)$.

$\mathrm{Ke}$ is the so-called Kelvin term, which accounts for enhancements in vapor pressure due to surface curvature. In Eq. (3) we have used the common assumption that the partial molar volume of water can be approximated by $M W_{w} / \rho_{w}$. In these equations $s$ is the saturation ratio $(=R H / 100), a_{w}$ is the water activity of the solution droplet, $\sigma_{\mathrm{sol}}$ is the surface tension of the solution, $M W_{w}$ is the molecular weight of water, $R$ is the universal gas constant, $T$ is the temperature, and $\rho_{w}$ is the density of water.

The application of Eq. (2) requires information about the water activity of the solution constituting the drop. The water activity may be expressed as

$a_{w}^{-1}=1+v \Phi \frac{n_{s}}{n_{w}}$

where $n_{s}$ is the moles of solute, $n_{w}$ is the moles of water, $v$ is the number of ions each solute molecule dissociates into, and $\Phi$ is the osmotic coefficient, which expresses solution nonidealities. Molecular structure indicates the value of $v$ for complete dissociation under infinitely dilute conditions. However, these organics are only weakly dissociating, and a more representative value for $v$ can be approximated from the first dissociation constant, $K_{a}$, and the initial solution molality, $m_{o}$ :

$K_{a}=\frac{\lambda^{2}}{m_{o}-\lambda}$,

where $\lambda$ is the extent of dissociation, and $v$ is equal to $\left(m_{o}+\lambda\right) / m_{o}$. Values of these parameters for the compounds studied here are listed in Table 1. Although the constants for the second- and higher-dissociations should be included in the calculation of $\lambda$, for simplicity we show estimates based

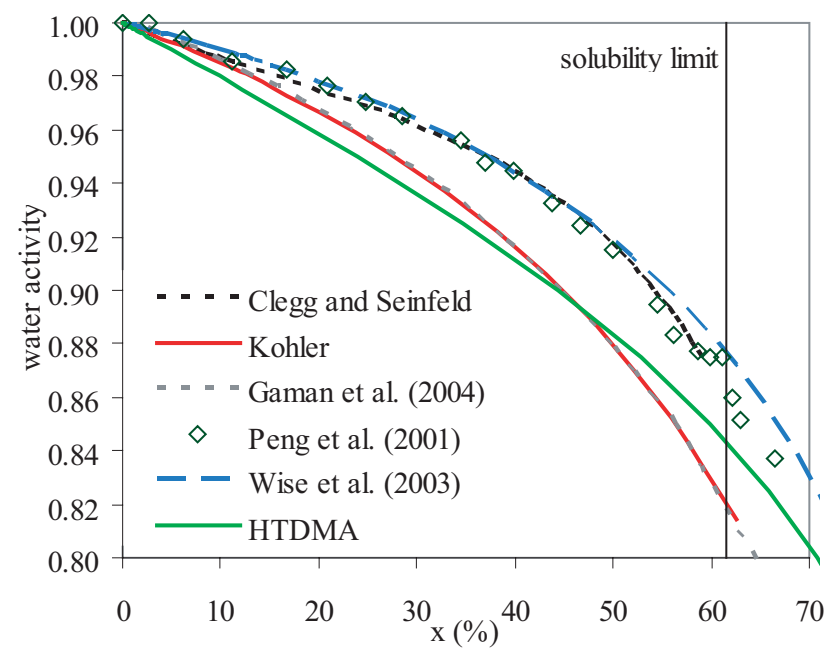

Fig. 4. Water activity as a function of glutaric acid wt \%. HTDMA: this study $(\mathrm{T}=303 \mathrm{~K})$. Other relationships shown are from Gaman et al. (2004); Peng et al. (2001a); Wise et al. (2003); Köhler theory with $\nu=1$ (Kreidenweis et al., 2005); and Clegg and Seinfeld $(2005)^{1}$. All estimates at $298.15 \mathrm{~K}$ unless otherwise specified.

only on the stronger, first dissociation. In previous studies of the activation of particles of pure organic species to cloud drops, $v$ was assumed to be one (Corrigan and Novakov, 1999; Raymond and Pandis, 2002b). This is likely a reasonable assumption for glutaric and malonic acids, but not for oxalic acid, as can be seen from Table 1. Similar conclusions were reached by Kumar et al. (2003) and Ervens et al. (2004). Information on the dissociation of levoglucosan is not available, however, the high $\mathrm{pKa}$ values for fructose and glucose indicate that their dissociation is very weak and thus $\nu=1$ is likely to be a good assumption for all of these sugars.

The $G F$ as a function of $a_{w}$ is fit to an equation of the form (Kreidenweis et al., 2005)

$G F=\left[1+\left(a+b \cdot a_{w}+c \cdot a_{w}^{2}\right) \frac{a_{w}}{1-a_{w}}\right]^{\frac{1}{3}}$.

The HTDMA measures $G F(R H)$, so an assumption is needed to relate $R H$ in the instrument to $a_{w}$ of the solution. The simplest assumption is that the Kelvin term is 1 in Eq. (2). For $100 \mathrm{~nm}$ particles and typical growth factors, this generally leads to a $1-2 \%$ error in the water activity. In this work, however, we have corrected all HTDMA data by evaluating the Kelvin term (Eq. 3) for the wetted droplet size at each point using known composition-dependent solution surface tensions, if available (Table 1).

The surface tensions of levoglucosan solutions at varying concentrations were measured in our lab using a Central Scientific Company Tensiometer (Model 70535), but were not found to be significantly lower than the surface tension of pure water $\left(0.072 \mathrm{~J} \mathrm{~m}^{-2}\right)$, within the error of the measurement. Tuckermann and Cammenga (2004) also found that 
levoglucosan solutions had a roughly constant surface tension near $0.073 \mathrm{~J} \mathrm{~m}^{-2}$ over a range of $0.001-10 \mathrm{mg} \mathrm{mL}^{-1}$. However, Chen et al. (2002) reported that glucose could lower the surface tension of a solution to about $0.060 \mathrm{~J} \mathrm{~m}^{-2}$ at $40 \mathrm{wt} \%$. In our calculations, we assume that all sugar solutions have a surface tension equal to pure water.

Part I describes how water activity is expressed in terms of solute mass fraction, $x$, using the dry particle density. We have applied this methodology to the data presented here in order to compare with other estimates of $a_{w}(x)$ and to compute $\sigma_{\text {sol }}(x)$ (Table 1). However, we note that extrapolation of the fitted $G F-a_{w}$ relationship to very dilute conditions, used to determine the critical wet diameter and critical supersaturation for a particular choice of dry diameter, is the same regardless of the choice of dry density if it is assumed that $\sigma_{\mathrm{sol}}(x)$ is equal to the surface tension of pure water, $\sigma_{w}(x)$. The direct extrapolation involves maximizing $s$ as in Eq. (2) as $a_{w}$ is incremented toward 1, evaluating $G F\left(a_{w}\right)$ and thus $D_{\text {wet }}$ based on the fitted $G F-a_{w}$ relationship. Use of HTDMA data to infer water activity relies on applicability of the assumption of volume additivity, since increases in particle volume with RH are interpreted as due solely to the addition of that volume of water. The assumption of volume additivity is generally expected to be good for the solutions considered here.

\section{Determination of solution water activities and estima- tion of CCN activity}

\subsection{Water activity}

Using the method described above, solution water activities for glutaric, malonic and oxalic acids and levoglucosan were estimated and compared to previously-published data.

\subsubsection{Dicarboxylic acids}

Several previous studies have estimated the water activity of aqueous solutions of dicarboxylic acids. These estimates are compared to those obtained from the HTDMA data in Figs. 4 through 6. The Wise et al. (2003) relationship is computed from their suggested fit to water activities derived from vapor pressure measurements. Peng et al. (2001a) exposed supermicron particles to controlled relative humidities in an electrodynamic balance (EDB), and deduced composition from particle mass measurements. For dilute solutions, measurements were made on bulk solutions using a water activity meter. Gaman et al. (2004) fitted data from Davies and Thomas (1956) to the van Laar equations and reported the values of the coefficients for glutaric acid, used to compute water activities. The Clegg and Seinfeld model refers to results computed from a thermodynamic model that includes the dissociation of the acids, and is based upon available water activity and osmotic coefficient data for each acid at $298.15 \mathrm{~K}$ (Clegg and Seinfeld, $2005^{1}$ ). We also show the water activity effectively assumed in the simplified Köhler equation, that is, Eq. (4) assuming $\nu=1$ and $\Phi=1$ (Kreidenweis et al., 2005). In each Figs. 4 through 6, the estimated concentrations of the saturated solutions of the acid in pure water, as tabulated in Table 1, are indicated as vertical lines.

For glutaric acid (Fig. 4), the water activities from Köhler theory and Gaman et al. (2004) match the HTDMA-derived estimates reasonably well, whereas the experimental results from Peng et al. (2001a) and Wise et al. (2003) and the predictions from the Clegg and Seinfeld model are similar to each other, but differ from the other estimates. However, Clegg and Seinfeld (2005) ${ }^{1}$ incorporated data from Peng et al. (2001a) and Wise et al. (2003) in their model. For malonic acid (Fig. 5), the Clegg and Seinfeld model agrees with the data of Peng et al. (2001a) and Hansen and Beyer (2004), which are also well represented with the assumption of $\nu=1$ in the Köhler equation. Results for oxalic acid are shown in Fig. 6. Prior experimental studies have deduced that particles of the metastable oxalic acid dihydrate were often created in the laboratory, instead of the anhydrous state (Kumar et al., 2003; Prenni et al., 2001). The formation of the dihydrate state appears to make these particles more stable than the oxalic acid particles (i.e., reduces vapor pressure) and therefore very little evaporation is seen for these particles. For the reduction of HTDMA data, the droplet composition may be determined from the $\mathrm{RH}$-dependent growth factors for oxalic acid either using the raw data, corrected for the Kelvin term as indicated above, or by applying an additional correction to the dry diameter by removing the bound water mass, assuming the particle is in the dihydrate state:

$D_{\text {eq }}^{3}=\frac{M W_{\text {anhyd }}}{M W_{\text {dihyd }}} \frac{\rho_{\text {dihyd }}}{\rho_{\text {anhyd }}} D^{3}$

where $D_{\text {eq }}$ is the equivalent diameter corresponding to anhydrous oxalic acid, $M W_{\text {anhyd }}$ is the molecular weight of oxalic acid, $M W_{\text {dihyd }}$ is the molecular weight of the dihydrate, $\rho_{\text {dihyd }}$ is the density of the dihydrate, and $\rho_{\text {anhyd }}$ is the density of anhydrous oxalic acid (Table 1). Results for both assumptions are shown in Fig. 6. All predictions are similar to the Peng et al. (2001a) measurements at high dilution, but diverge for supersaturated solutions.

In Figs. 4 and 5, the HTDMA-derived water activities for dilute aqueous solutions of glutaric and malonic acids are the lowest among the presented data. If the assumed adjustment in dry particle size that normalizes all GFs to 1 at low $R H$ is too large, then the water activity at each wt \% will be under-predicted. In Fig. 5 we also show, for comparison, the water activities for malonic acid solutions that have been derived without the adjustment of the $G F$ s. This magnitude

\footnotetext{
${ }^{1}$ Clegg, S. L. and Seinfeld, J. H.: Thermodynamic models of aqueous solutions containing inorganic electrolytes and dicarboxylic acids at $298.15 \mathrm{~K}$. I. The acids as non-dissociating components, in preparation, 2005.
} 


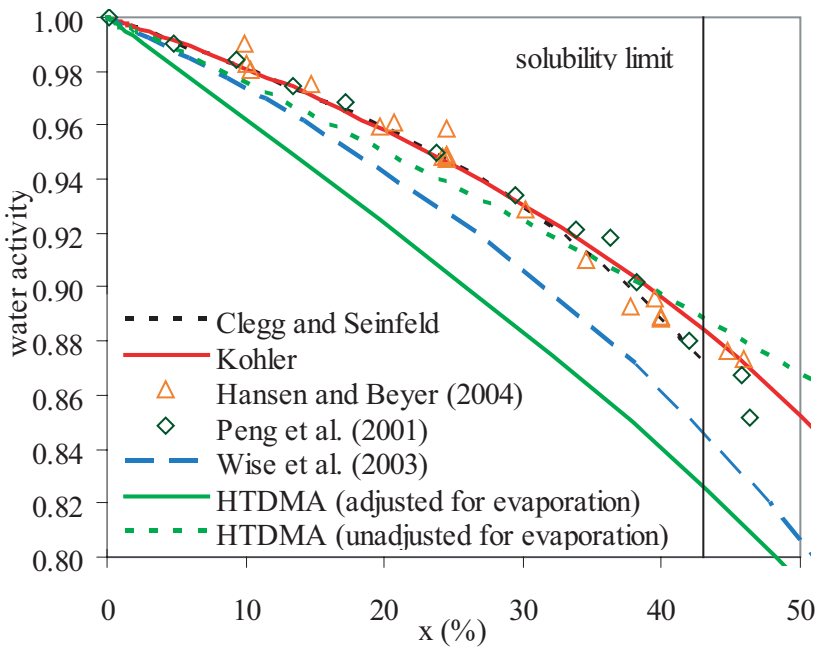

Fig. 5. Water activity as a function of malonic acid wt $\%$. HTDMA: this study (with and without evaporation adjustment, $\mathrm{T}=303 \mathrm{~K}$ ). Other relationships shown are from Hansen and Beyer (2004) ( T=220 K); Peng et al. (2001a); Wise et al. (2003); Köhler theory with $v=1$ (Kreidenweis et al., 2005); and Clegg and Seinfeld $(2005)^{1}$. All estimates at $298.15 \mathrm{~K}$ unless otherwise specified.

of shift is similar for glutaric acid. As noted above, if the adjustment is required because of evaporative losses at low $R H$, the adjustment may be too large for data taken at higher $R H$ (more dilute conditions) where evaporation is less of an issue. In subsequent sections we explore the inferences to $\mathrm{CCN}$ activity of these uncertainties in $G F$ as propagated into uncertainties in water activities.

\subsubsection{Levoglucosan}

Water activity data for aqueous levoglucosan solutions have been published by Chan et al. (2005). We also show data for glucose and fructose for comparison with our HTDMAderived estimates. Peng et al. (2001b) suspended drops of aqueous solutions of glucose at controlled RH in an electrodynamic balance and deduced composition from particle mass measurements. Bhandari and Bareyre (2003) used a water activity meter with a sensitivity of 0.001 . Ferreira et al. (2003) compiled osmotic coefficient and water activity experimental data from Lerici et al. (1983), Miyajima et al. (1983), Rüegg and Blanc (1981) and Scatchard et al. (1938) for fructose and glucose and compared measurements with predictions from a modified UNIFAC model. Comesaña et al. (2001) measured water activity with a Thermo-constanter electric hygrometer with an average absolute error of \pm 0.005 . These prior studies are summarized in Figs. 7 and 8. For comparison, also shown are the water activities effectively assumed in Köhler theory (for levoglucosan) when $v \Phi$ is assumed to be equal to unity.

Water activity may also be derived from freezing point

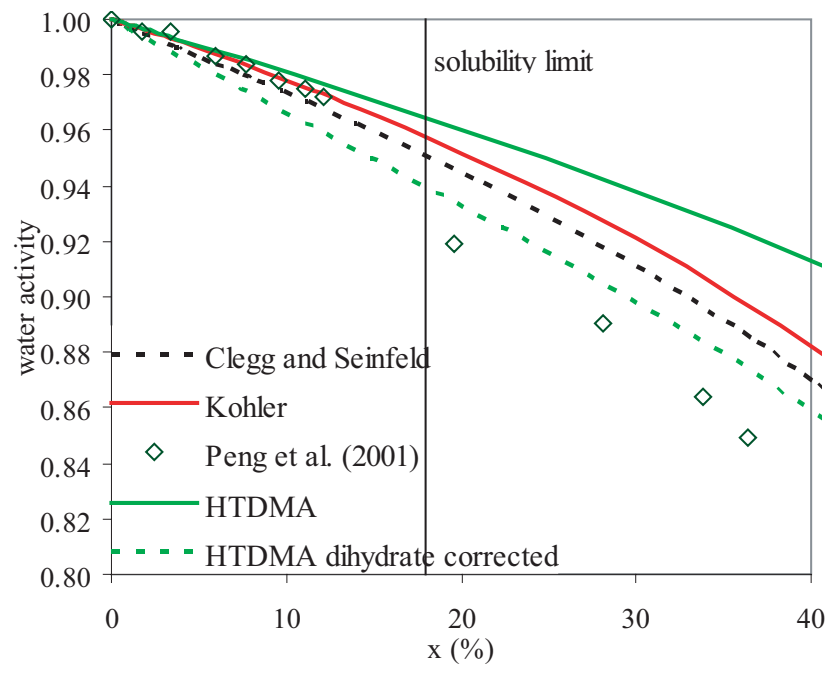

Fig. 6. Water activity as a function of oxalic acid wt \%. HTDMA: this study (anhydrous and dihydrate assumptions, T=303 K). Other relationships shown are from Peng et al. (2001a); Köhler theory with $\nu=1$ (Kreidenweis et al., 2005); and Clegg and Seinfeld $(2005)^{1}$. All estimates at $298.15 \mathrm{~K}$ unless otherwise specified.

depression measurements. Following Robinson and Stokes (1959), the equilibrium condition for a solution composed of a pure solute, which freezes at temperature $T_{F}$ is:

$\Delta \bar{G}_{T_{F}}+R T_{F} \ln a_{w}=0$,

where $\Delta \bar{G}_{T_{F}}$ is the increase in free energy on the fusion of a mole of ice to pure liquid water at $T_{F}$. Using the GibbsHelmholtz equation:

$\frac{\partial}{\partial T}\left(\frac{\Delta \bar{G}}{T}\right)=-\frac{\bar{L}}{T^{2}}$

and approximating the latent heat of fusion dependence on temperature as:

$\bar{L}=L_{0}+J\left(T_{F}-T_{0}\right)$,

where $L_{0}$ is the latent heat of fusion at $T_{0}$ and $J$ is the difference in molal heat capacities between liquid water and ice and is assumed to be independent of temperature, the water activity can be approximated as:

$-\log a_{w}=0.004207 \theta+2.1 \times 10^{-6} \theta^{2}$,

where $\theta=T_{0}-T_{F}$ is the freezing point depression below the freezing point of pure water $\left(T_{0}=273.15 \mathrm{~K}\right)$. The water activity obtained from Eq. (11) is the water activity at the freezing temperature, however, it is generally a good assumption that the water activity is only a weak function of temperature. Freezing point depression data for glucose and fructose are reported in the CRC Handbook of Chemistry and Physics (Lide, 2000). 


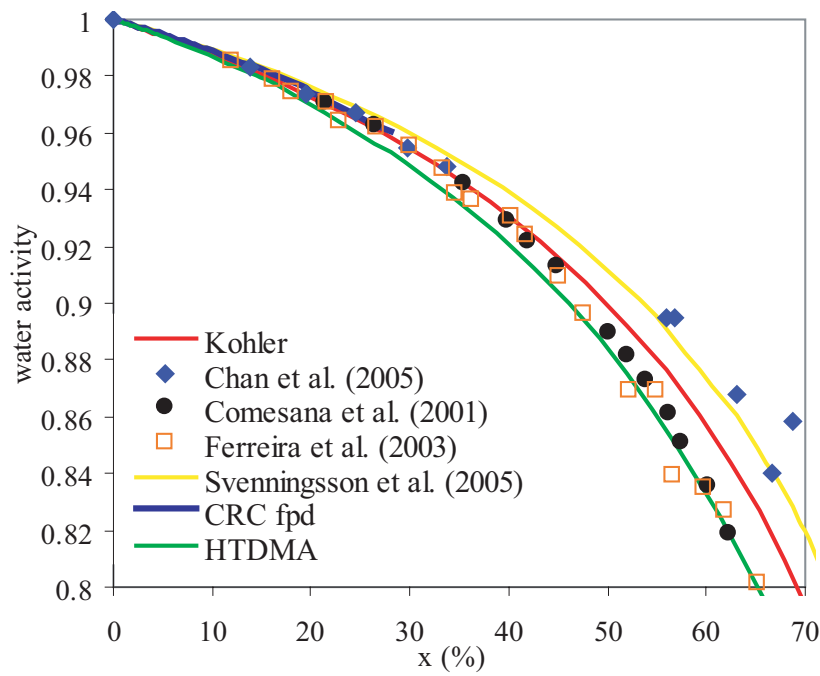

Fig. 7. Water activity as a function of levoglucosan wt \%. HTDMA: this study. Köhler theory with $\nu=1$ (Kreidenweis et al., 2005) calculated for levoglucosan. Water activity measured by Chan et al. (2005) is for levoglucosan solutions. Svenningsson et al. (2005) is their reported polynomial for water activity deduced from GF measurements. Other relationships shown are for fructose solutions: freezing point depression (CRC fpd) derived water activity (Lide, 2000, freezing temperature); Comesaña et al. (2001), $\mathrm{T}=308 \mathrm{~K}$; and Ferreira et al. (2003). All estimates at 298.15 K unless otherwise specified.

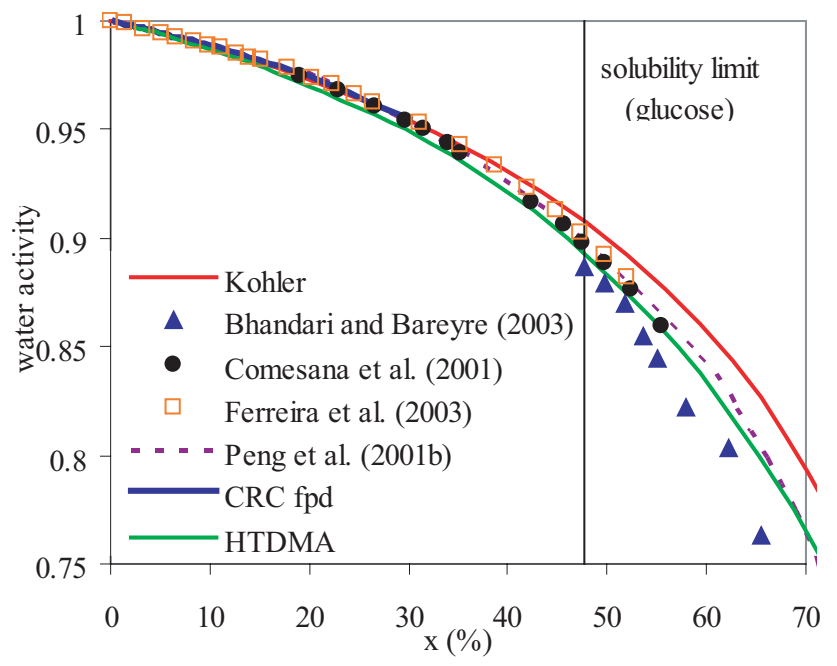

Fig. 8. Water activity as a function of levoglucosan wt \%. HTDMA: this study. Köhler theory with $v=1$ (Kreidenweis et al., 2005) calculated for levoglucosan. Other relationships shown are for glucose: freezing point depression (CRC fpd) derived water activity (Lide, 2000, freezing temperature); Bhandari and Bareyre (2003); Ferreira et al. (2003); Comesaña et al. (2001), T=308 K; and Peng et al. (2001b). All estimates at $298.15 \mathrm{~K}$ unless otherwise specified.

Atmos. Chem. Phys., 6, 795-809, 2006

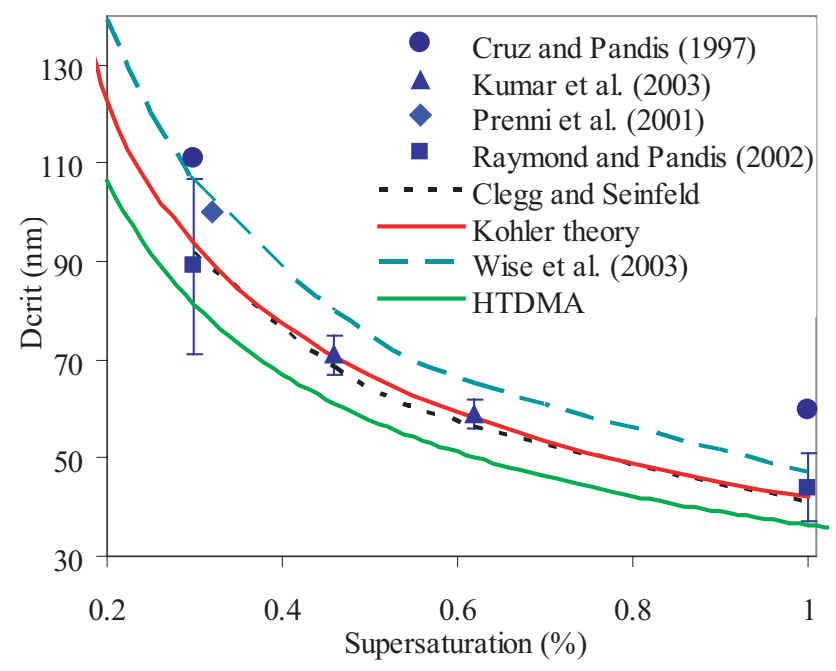

Fig. 9. Critical dry diameters as a function of supersaturation for glutaric acid. HTDMA: calculated using water activities derived in this study. Other theoretical relationships shown are from Köhler theory with $\nu=1$ (Kreidenweis et al., 2005); Clegg and Seinfeld $(2005)^{1}$; and Wise et al. (2003). Experimental points are from Cruz and Pandis (1997); Kumar et al. (2003); Prenni et al. (2001); and Raymond and Pandis (2002). Error bars are as reported in Raymond and Pandis (2002) and Kumar et al. (2003).

Figure 7 compares the water activity of levoglucosan solutions determined by Chan et al. (2005) and in this study using the HTDMA data with water activities of fructose solutions from the literature. While there is very good agreement between this study and the prior water activity estimates for fructose solutions, the measurements of Chan et al. (2005) diverge for more concentrated solutions. Very good agreement is also found comparing the HTDMA-estimated levoglucosan solution water activities with published water activity measurements for glucose solutions, as shown in Fig. 8. The results suggest that all three compounds - levoglucosan, glucose and fructose - have very similar solution water activities.

\subsection{Critical dry diameters}

Water activity estimates discussed in Sect. 4.1 are next used in the Köhler equation (Eq. 2) to predict the supersaturation required for activation of a dry particle. The minimum size of dry particle activated at a specified supersaturation is referred to as the critical dry diameter, $D_{\text {crit }}$, different from the critical diameter, which generally refers to the wetted droplet size at the specified critical supersaturation.

\subsubsection{Dicarboxylic acids}

We use the water activity data shown in Figs. 4 through 6 in Eq. (2) to predict $D_{\text {crit }}$ values, and compare to published 


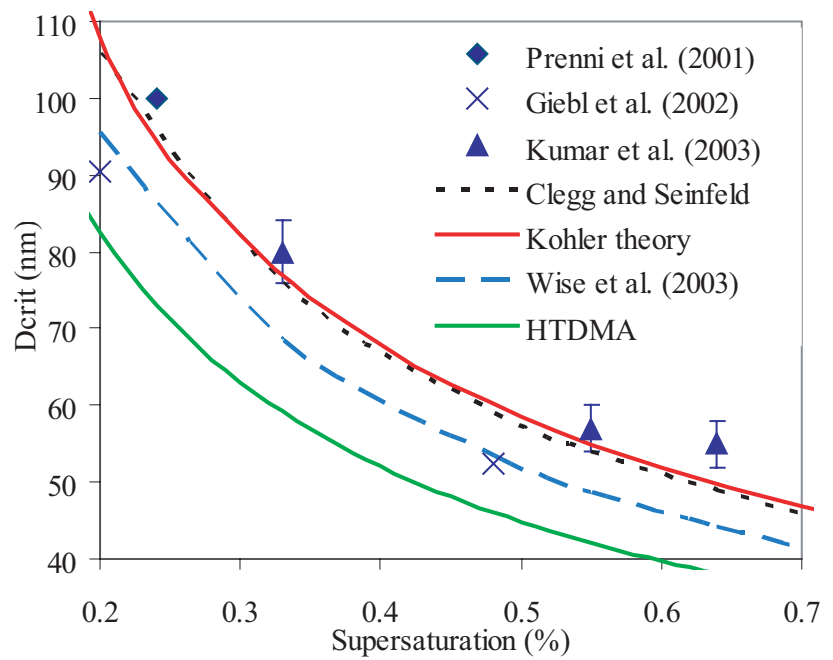

Fig. 10. Critical dry diameters as a function of supersaturation for malonic acid. HTDMA: calculated using water activities derived in this study. Other theoretical relationships shown are from Köhler theory with $v=1$ (Kreidenweis et al., 2005); Clegg and Seinfeld (2005) ${ }^{1}$; and Wise et al. (2003). Experimental points are from Prenni et al. (2001); Giebl et al. (2002); and Kumar et al. (2003), with error bars as reported in Kumar et al. (2003).

experimental cloud drop activation data for dicarboxylic acids as reported by Cruz and Pandis (1997), Prenni et al. (2001), Giebl et al. (2002), Raymond and Pandis (2002), and Kumar et al. (2003).

Results for glutaric acid are shown in Fig. 9. Prenni et al. (2001) and Cruz and Pandis (1997) found that larger dry particles were required for activation at the given supersaturations than those determined in other experimental studies. Prenni et al. (2001) attribute this to evaporation of the glutaric acid particles during delivery to the chamber, which was not measured or corrected for during their cloud condensation nuclei counter (CCNC) experiments. This evaporation can account for up to $20 \%$ of the mass, dropping the $D_{\text {crit }}$ into the range of other experimental points. Kumar et al. (2003) also found difficulties obtaining a stable particle size. The spread in the data and predictions shown in Fig. 9 should be compared with the estimated uncertainty for glutaric acid activation diameters reported by Raymond and Pandis (2002), which ranged from $\pm 7 \mathrm{~nm}$ at $1 \%$ supersaturation to $\pm 18 \mathrm{~nm}$ at $0.3 \%$ supersaturation. All predictions and data fall within these uncertainty ranges. Glutaric acid is the least active (requiring the largest critical dry diameter for a given supersaturation) of the dicarboxylic acids studied here.

Comparisons of experimental results and modeled $D_{\text {crit }}$ values for malonic acid are shown in Fig. 10. The HTDMAderived estimates of $D_{\text {crit }}$ are considerably smaller than the other predictions, as expected from the water activity estimates shown in Fig. 5. We note that if the adjustments for evaporation of dry particles are not made before deducing

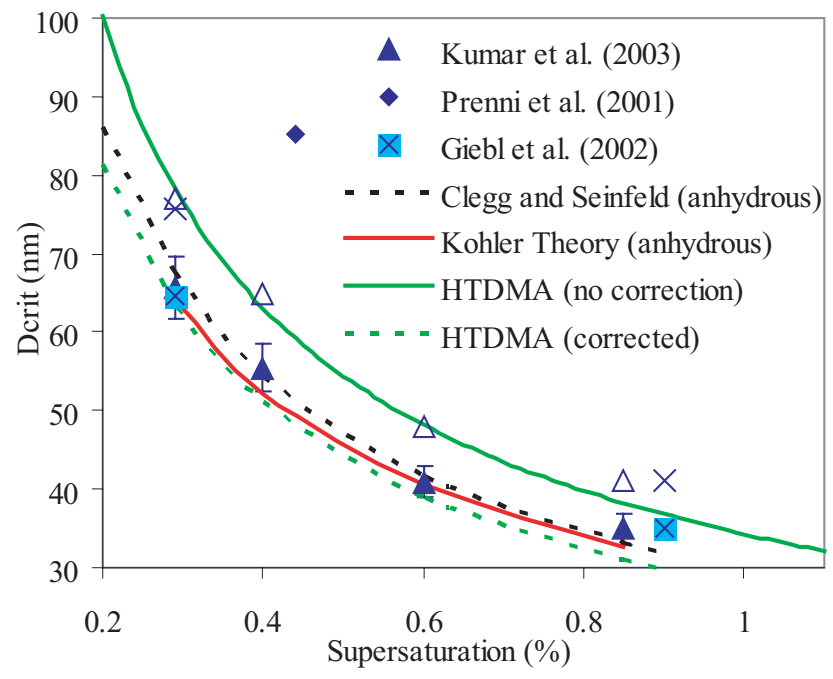

Fig. 11. Critical dry diameters as a function of supersaturation for oxalic acid. HTDMA: calculated using water activities derived in this study (anhydrous and dihydrate assumptions). Other theoretical relationships shown are from Köhler theory with variable $v$ (Kumar et al., 2003) and Clegg and Seinfeld (2005) ${ }^{1}$. Experimental points are from Prenni et al. (2001); Giebl et al. (2002); and Kumar et al. (2003). Open symbol experimental points refer to experimental data as published. Filled symbols have been corrected using Eq. (7) to account for the bound water in the dihydrate particles.

solution water activity as a function of composition, the predicted $D_{\text {crit }}$ values are nearly identical to those computed for the Wise et al. (2003) water activities. In other words, the two HTDMA-derived estimates of water activity for malonic acid solutions shown in Fig. 5 translate into an approximately $10 \mathrm{~nm}$ difference in critical dry diameter at typical atmospheric supersaturations. The experimental $\mathrm{CCN}$ data reported by Kumar et al. (2003) and Prenni et al. (2001) are similar to the predictions from Köhler theory and the Clegg and Seinfeld model. The Wise et al. (2003) parameterization predicts somewhat smaller diameters, close to the Giebl et al. (2003) observations. The spread between all of the various predictions and observations at $0.3 \%$ supersaturation, about $\pm 9 \mathrm{~nm}$, is significantly lower than the uncertainty reported by Raymond and Pandis (2002) for glutaric acid.

The critical dry diameters computed for HTDMA-derived water activities for glutaric and malonic acids shown in Figs. 9 and 10 appear to be somewhat underestimated, a direct consequence of the systematic shift in predicted water activities for the HTDMA-derived data, as compared with other estimates, that was noted in the previous section for these compounds. We believe these trends arise because the applied adjustment of $G F$ that accounts for evaporation of the semivolatile species is likely to be an overestimation of the evaporation at high $R H$. The value of $D_{\text {crit }}$ is most strongly influenced by the values of the $G F$ at high $R H$, and thus it is not surprising that while it is necessary to include 


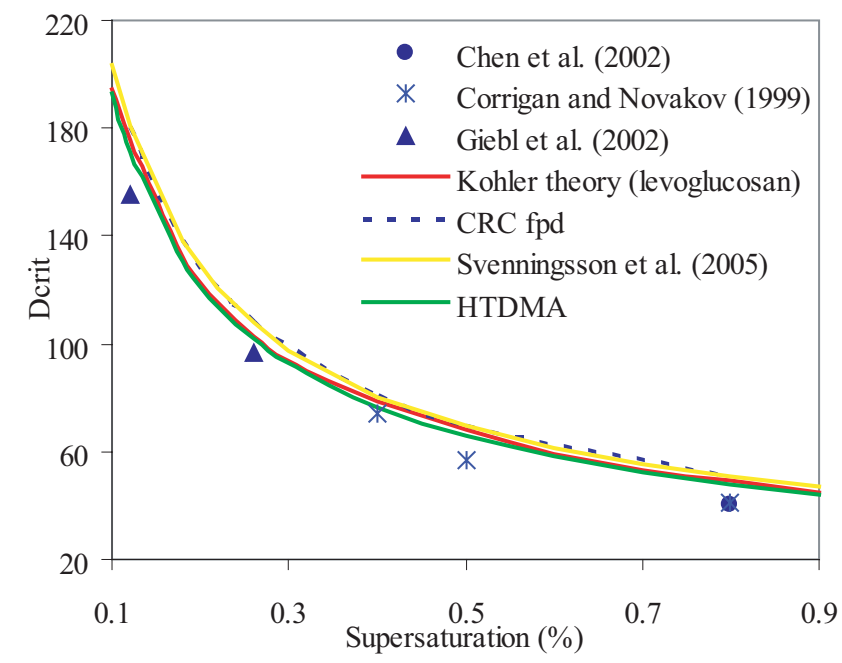

Fig. 12. Critical dry diameters as a function of supersaturation for levoglucosan. HTDMA: calculated using water activities derived in this study. Other theoretical relationships shown are from Köhler theory with $\nu=1$ (Kreidenweis et al., 2005), from freezing point depression (CRC fpd) derived water activity of glucose solutions (Lide, 2000), and from the parameterization of levoglucosan water activity by Svenningsson et al. (2005). Experimental points are from Chen et al. (2002), glucose; Corrigan and Novakov (1999), glucose; and Giebl et al. (2002), fructose.

the evaporation adjustment to get reasonable values of water activity below water saturation, neglecting this adjustment yields larger $D_{\text {crit }}$ values, generally in closer agreement to experimental data. Nevertheless, the spread in the estimates introduced by these uncertainties is still well within the typical experimental error for $\mathrm{CCN}$ measurements.

Observations and predictions of the critical supersaturation for oxalic acid particles are shown in Fig. 11. The point from Prenni et al. (2001) suggests a considerably higher $D_{\text {crit }}$ than any other experimental data. For the HTDMA-derived estimates, water activities derived from the two disparate assumptions about dry particle composition - anhydrous or dihydrate - were used to predict critical diameters. The assumption that the dry particles were anhydrous in the HTDMA experiments and required no correction to their volume for bound water yields predictions close to the experimental data as published, but quite different from the predictions from the Clegg and Seinfeld model, as was also seen in Fig. 4. However, it is possible that the particles used in the $\mathrm{CCN}$ experiments were in fact dihydrate particles. If the experimental dry diameters from the CCNC and HTDMA experiments are corrected to equivalent anhydrous oxalic acid particles, good agreement with the Clegg and Seinfeld model is found. Figure 11 suggests that the HTDMA data were indeed obtained for dihydrate particles, and the water activity relationship derived using this assumption to reduce the HTDMA data is more accurate. Simplified Köhler theory with $\nu=1$ overpredicts $D_{\text {crit }}$ compared to the experimental data, so the Köhler theory calculations reported by Kumar et al. (2003) are shown. These consider variable $v$ according to composition-dependent dissociation and yield $D_{\text {crit }}$ values very similar to the Clegg and Seinfeld model. The range of $D_{\text {crit }}$ values considering all models and estimates, except for the point due to Prenni et al. (2001), is about $\pm 10 \mathrm{~nm}$ at $0.3 \%$ supersaturation, similar to the range for malonic acid and considerably smaller than that for glutaric acid.

\subsubsection{Levoglucosan}

Critical dry diameters for levoglucosan are predicted from the HTDMA-derived water activity and compared to experimental results for glucose from Corrigan and Novakov (1999) and Chen et al. (2002), and for fructose from Giebl et al. (2002), in Fig. 12. Critical dry diameters are also predicted using 4th order polynomial parameterizations of the CRC freezing point depression derived water activities for glucose and fructose solutions, 4th order polynomial parameterizations of the water activities determined by Ferreira et al. (2003) for glucose and fructose, and the polynomial fit to water activity of levoglucosan given by Svenningsson et al. (2005). The estimates from the CRC freezing point depression data are so similar to the estimates from Ferreira et al. (2003) for both glucose and fructose that only the CRCderived $D_{\text {crit }}$ values of glucose are shown for clarity. Predictions of levoglucosan critical dry diameters by simplified Köhler theory, assuming $v \Phi=1$, are also shown in Fig. 12. The fit for water activity for glucose solutions suggested by Peng et al. (2001b) is not used, as the reported water activity polynomials are only valid for $a_{w}<0.98$.

The calculated $D_{\text {crit }}$ values of levoglucosan correspond quite well to the experimental measurements. All of the data and estimates shown in Fig. 12 are in reasonably good agreement, with a spread of $\pm 6 \mathrm{~nm}$ at $0.3 \%$ supersaturation, significantly less than the error reported by Raymond and Pandis (2002) for glutaric acid. Similar to the conclusion for solution water activities, it appears that all three sugars have essentially the same activity as CCN.

\section{Parameterization of CCN activity of species studied}

Assuming the applicability of Köhler theory, the following relationship between the supersaturation and the critical dry diameter can be derived (Kreidenweis et al., 2005):

$$
\begin{aligned}
& D_{\text {crit }}=\left(\frac{256 j^{3}}{27 k}\right)^{1 / 3} \times S_{\text {crit }}^{-2 / 3}=\beta \times S_{\text {crit }}^{-2 / 3} \\
& j=\left(\frac{\sigma_{w} M W_{w}}{R T \rho_{w}}\right) \\
& k=\frac{\nu \Phi \rho_{s} M W_{w}}{M W_{s} \rho_{w}}
\end{aligned}
$$

Values of $\beta$ can be computed from knowledge of the species dry density and molecular weight, and appropriate assumptions for the values of $v$ and $\Phi$ at activation. In Table 2, 
Table 2. Parameterization of results for critical dry diameters for activation as a cloud drop (Eqs. 12 and 13). $\alpha$ is the best-fit parameter for HTDMA-derived water activities (Eq. 14) and $\beta$ is the parameter calculated for Eq. (12) for the indicated assumption of $\nu$, with $\Phi=1$. HTDMA data reduction uses Kelvin correction with solution surface tension; other conditions shown in Notes. All calculations are at $298.15 \mathrm{~K}$.

\begin{tabular}{|c|c|c|c|c|c|}
\hline Species & $\alpha$ & $\beta$ & $\begin{array}{l}\text { Deduced } v \Phi \text { from } \\
\text { HTDMA }\end{array}$ & $\begin{array}{l}\text { Deduced } \nu \Phi \text { from } \\
\text { best fit to predictions of } \\
\text { Clegg and Seinfeld (2005) } \\
\text { model (except where noted) }\end{array}$ & Notes \\
\hline ammonium sulfate & 31.44 & $\begin{array}{l}26.58 \\
(\nu=3)\end{array}$ & 1.81 & 2.46 (AIM) & \\
\hline sodium chloride & 21.47 & $\begin{array}{l}21.68 \\
(\nu=2)\end{array}$ & 1.84 & 1.91 (AIM) & $\begin{array}{l}\text { HTDMA data corrected } \\
\text { for shape factor }\end{array}$ \\
\hline glutaric acid & $\begin{array}{l}36.42 \\
39.08\end{array}$ & $\begin{array}{l}41.14 \\
(v=1)\end{array}$ & $1.37,1.16$ & 0.97 & $\begin{array}{l}\text { Two values shown in } \\
\text { second and fourth columns } \\
\text { are with/without evaporation } \\
\text { adjustment }\end{array}$ \\
\hline malonic acid & $\begin{array}{l}28.24 \\
32.93\end{array}$ & $\begin{array}{l}36.38 \\
(\nu=1)\end{array}$ & $2.14,1.35$ & 1.01 & $\begin{array}{l}\text { Two values shown in } \\
\text { second and fourth columns } \\
\text { are with/without evaporation } \\
\text { adjustment }\end{array}$ \\
\hline oxalic acid & 34.26 & $\begin{array}{l}32.94 \\
(\nu=1)\end{array}$ & 0.89 & 1.39 & \\
\hline oxalic acid & 27.89 & $\begin{array}{l}32.94 \\
(v=1)\end{array}$ & 1.65 & 1.39 & $\begin{array}{l}\text { Dihydrate form assumed } \\
\text { for HTDMA data reduction; } \\
\text { corrected to anhydrous form } \\
\text { for fitting }\end{array}$ \\
\hline levoglucosan & 41.53 & $\begin{array}{l}42.09 \\
(\nu=1)\end{array}$ & 1.04 & - & \\
\hline
\end{tabular}

we show computed values of $\beta$ for the standard assumptions used in standard Köhler theory, namely, $\Phi=1$ and values of $v$ as indicated in the table.

Based on the form of Eq. (12), we have also fit $D_{\text {crit }}-S_{\text {crit }}$ relationships to the following form:

$D_{\text {crit }}=\alpha \times S_{\text {crit }}^{-2 / 3}$,

where $\alpha$ is a best fit parameter for $D_{\text {crit }}$ expressed in nanometers and $S_{\text {crit }}$ expressed as supersaturation percentage. We deduced values of $\alpha$ from the $D_{\text {crit }}-S_{\text {crit }}$ relationships derived from the HTDMA water activity estimates; these are listed in the second column of Table 2 .

We can compare the best-fit values of $\alpha$ to the components of $\beta$ as shown in Eq. (12). Since all terms in Eq. (12) except $\nu \Phi$ are fixed properties of either water or the solute, we can deduce the values of $\nu \Phi$ required to yield the best-fit $\alpha$. These are shown in the fourth column of Table 2. Further, we can perform a similar calculation to derive the $\nu \Phi$ that is consistent with the $D_{\text {crit }}-S_{\text {crit }}$ relationships computed using the best available models of solution water activities. The best available models were taken as AIM Model III (Clegg et al., 1998) for the inorganics, and the model reported by Clegg and Seinfeld $(2005)^{1}$ for the dicarboxylic acids. The values of $\nu \Phi$ for the best available models are shown in the fifth column of Table 2 .
The assumption of $\nu=3$ is known to be an overestimate of the dissociation for ammonium sulfate (Gerber et al., 1977), so it is not surprising that HTDMA-derived water activities correspond to $v \Phi=1.81$ as a better approximation. For comparison, AIM Model III corresponds to $v \Phi=2.46$. The HTDMA method overpredicts the $D_{\text {crit }}$ values for ammonium sulfate compared with both measurements and the predictions from AIM, and thus a lower value for $\nu \Phi$ is inferred. In contrast, the standard Köhler theory approximation for $\mathrm{NaCl}$ $(\nu \Phi=2)$ is close to that derived from the HTDMA data, and is also consistent with AIM. For glutaric and malonic acids, the values of $\nu \Phi$ are overestimated by the HTDMA data when the $G F$ data are adjusted for evaporation, as can be seen by the underestimation of $D_{\text {crit }}$ in Figs. 9 and 10, but are much closer to one without evaporation adjustment. The Clegg and Seinfeld model also predicts that $\nu \Phi$ should be close to 1 at activation. Oxalic acid appears to have $\nu \Phi=1$, if HTDMA data are not corrected for the hydrate form, and $\nu \Phi=1.65$ if this correction is applied. The latter is similar to the value deduced at the critical supersaturation by Kumar et al. (2003), and predicted by the Clegg and Seinfeld model. Based on the available data, the standard assumption of $\nu \Phi=1$ appears to be reasonable for levoglucosan. 
Table 3. Largest and smallest derived $k$ values (Eq. (12)) for various compounds, and corresponding percent change in critical dry diameter for this range. Except for ammonium sulfate, sodium chloride and levoglucosan, largest $k$ values are derived from HTDMA data, reduced using the standard assumptions described in the text. Except where indicated otherwise, smallest $k$ values are derived from HTDMA data, but omitting adjustments for evaporation shrinkage and Kelvin effects.

\begin{tabular}{llll}
\hline Species & Largest $k$ & Smallest $k$ & \% change in Dcrit \\
\hline sodium chloride & 1.33 (Köhler) & 0.91 & 5.1 \\
ammonium sulfate & 0.72 (Köhler) & 0.33 & 20.5 \\
malonic acid & 0.60 & 0.28 (Köhler ) & 23.3 \\
oxalic acid (dihydrate) & 0.60 & 0.38 (Köhler) & 17.1 \\
glutaric acid & 0.28 & 0.12 (Wise et al., 2003) & 24.2 \\
levoglucosan & 0.18 (Köhler) & 0.15 & 5.7 \\
\hline
\end{tabular}

\section{Effect on drop number concentration}

The data presented in Figs. 9 through 12 and in Table 2 suggest that considerable uncertainty exists in estimates of critical supersaturation required to activate particles and form cloud drops, particularly for organic compounds. In evaluating the required accuracy of the water activity data and corresponding critical dry diameters used for interpreting aerosol effects on clouds, it is instructive to look at the change in drop number concentrations induced solely by the uncertainties in these quantities. We obtain an estimate of the number of cloud drops formed on an initial dry aerosol distribution with fixed physical characteristics, but varying hygroscopic properties, by simulating cloud drop formation during an adiabatic ascent.

For these simulations, we employ the parcel model developed by Feingold and Heymsfield (1992) and most recently applied by Ervens et al. (2004) and Ervens et al. (2005). Ervens et al. (2005) used this model to explore a large parameter space and examine the influence of changes in individual terms in the Köhler and droplet growth equations on predicted drop number concentrations, using ammonium sulfate as the base case against which all changes were compared. Our approach here is similar but more limited in parameter space, and is linked directly to the variations in $a_{w}(x)$ displayed for individual compounds as shown in Figs. 4 through 8. The model is initialized with a dry lognormal aerosol size distribution having a number geometric mean diameter of $0.08 \mu \mathrm{m}$ and a standard deviation of 2 . For each run, we assumed an initial particle number concentration of either 100 or $5000 \mathrm{~cm}^{-3}$, composed entirely of the solute of interest. The initial parcel thermodynamic conditions correspond to a height of $300 \mathrm{~m}$, a temperature of $15^{\circ} \mathrm{C}$ and a $R H$ of $85 \%$ to which the dry aerosol was equilibrated at time zero. All solutes are considered to be fully soluble and capable of existing as metastable solutions (i.e., their solution water activity expressions were assumed valid for $R H \geq 85 \%$ ). The parcel temperature and pressure are then varied in time to simulate adiabatic ascent, with the time-dependencies corresponding to one of two updraft velocities, 15 or $150 \mathrm{~cm} \mathrm{~s}^{-1}$. The model computes water saturation ratios, uptake of water by the solution particles, and depletion of water vapor as condensation proceeds by numerically integrating the equations describing these time-dependent changes in the gas and particle/cloud phases. Solution particles exceeding 1 micron in diameter are classified as cloud drops. We report the maximum number of cloud drops formed in each simulation, regardless of the time or liquid water content to which these maxima correspond.

To evaluate the effects of uncertainties in the water activity expression for a particular compound, we apply the two estimates that diverged most widely in the dilute concentration range. For each compound, we thus show results for 8 simulations that span high and low number concentrations, slow and fast updraft velocities, and upper and lower bounds on solution water activity. We use the parameter $k$ shown in Eq. (12) as a surrogate for the hygroscopicity of each compound, as it incorporates the information on solute density, molecular weight, and $\nu \Phi$ at activation. As described for the cases shown in Table 2 , we can fit the $D_{\text {crit }}-S_{\text {crit }}$ relationships computed for any estimate of water activity to the form of Eqs. (12) or (13), and thus deduce the value of $\nu \Phi$ and hence $k$ corresponding to that estimate. We then examine the variation in $k$ for an individual compound, as well as the variability in $k$ between the various compounds studied here, and relate these variations in hygroscopicity to variations in drop number as predicted from the parcel model runs. Table 3 lists the water activity estimates used as the upper and lower bounds for each compound and the corresponding $k$ values, and also indicates the percent change in $D_{\text {crit }}$ between model runs for an individual compound using these bounds. The HTDMA-derived water activities frequently represent one of the bounding values; the other bound is either represented by simplified Köhler theory or, for glutaric acid, using the estimate from Wise et al. (2003). The uncertainty in $k$ for a particular compound leads to $5-25 \%$ changes in $D_{\text {crit }}$. This percent change in critical dry diameter is computed at $S_{c}=0.3 \%$ but is roughly constant with supersaturation. The 
uncertainties in CCNC measurements of $D_{\text {crit }}$ at $S_{c}=0.3 \%$ for a variety of compounds, as reported by Raymond and Pandis (2002), is approximately $20 \%$, so the uncertainty in calculated $D_{\text {crit }}$ generated by uncertain water activity data is similar to that for the direct measurements.

In Fig. 13, we show that these variations in $k$ and $D_{\text {crit }}$ lead to $0-21 \%$ changes in predicted drop number concentrations for individual species, as indicated by the size of each bubble. The variations are larger for higher initial particle number concentrations, and largest for low updraft velocities. We also infer from the results shown in Fig. 13 that only variations in $k$ of more than about a factor of 2 lead to significant differences - that is, larger than about $15 \%$ - in predicted drop number concentrations. For example, while oxalic acid, malonic acid, and ammonium sulfate (median $k, 0.38$ ) activate similar numbers of drops for the conditions studied, sodium chloride (median $k, 1.12$ ) is clearly a better $\mathrm{CCN}$, activating a higher percentage of particles under all studied conditions, while glutaric acid and levoglucosan (median $k$, 0.17 ) are poorer $\mathrm{CCN}$. This grouping is also seen in the $G F$ data for these species (Fig. 1); there is about a 20\% increase in $G F(R H=85 \%)$ from the levoglucosan/glutaric acid grouping to the ammonium sulfate, oxalic acid and malonic acid grouping, and another $40 \%$ increase from the latter grouping to the sodium chloride $G F$. Although the simulations shown here are limited in scope - only one dry size distribution and a limited range of particle concentrations and updraft velocities are investigated - they are qualitatively similar to the findings of Ervens et al. (2005). In their study, Ervens et al. (2005) determined that drop number concentrations were most sensitive to variations in composition for cases with very low updraft velocities and high initial aerosol number concentrations. For broad regions of the studied parameter space, little to no variation in the number of activated drops was induced by varying $\nu \Phi$ or $M W_{s}$. Further, if all other properties were held constant, only variations in $\nu \Phi$ that at least doubled its base-case value (equivalent to doubling the value of $k$ ) led to changes in drop number concentration larger than $15 \%$.

From these simulations, we conclude that, although HTDMA-derived water activities may not be as accurate as other laboratory estimates, they are likely to be accurate enough to provide useful data for estimating the $\mathrm{CCN}$ properties of atmospheric particles. The $G F$ data distinguish differences in hygroscopicity (represented here by the parameter $k$ ) that are large enough to induce significant $(>15 \%)$ changes in drop number concentration in an adiabatic updraft, and that are large enough to exceed the differences that could be attributed to uncertainties in the direct measurement of CCN activity.
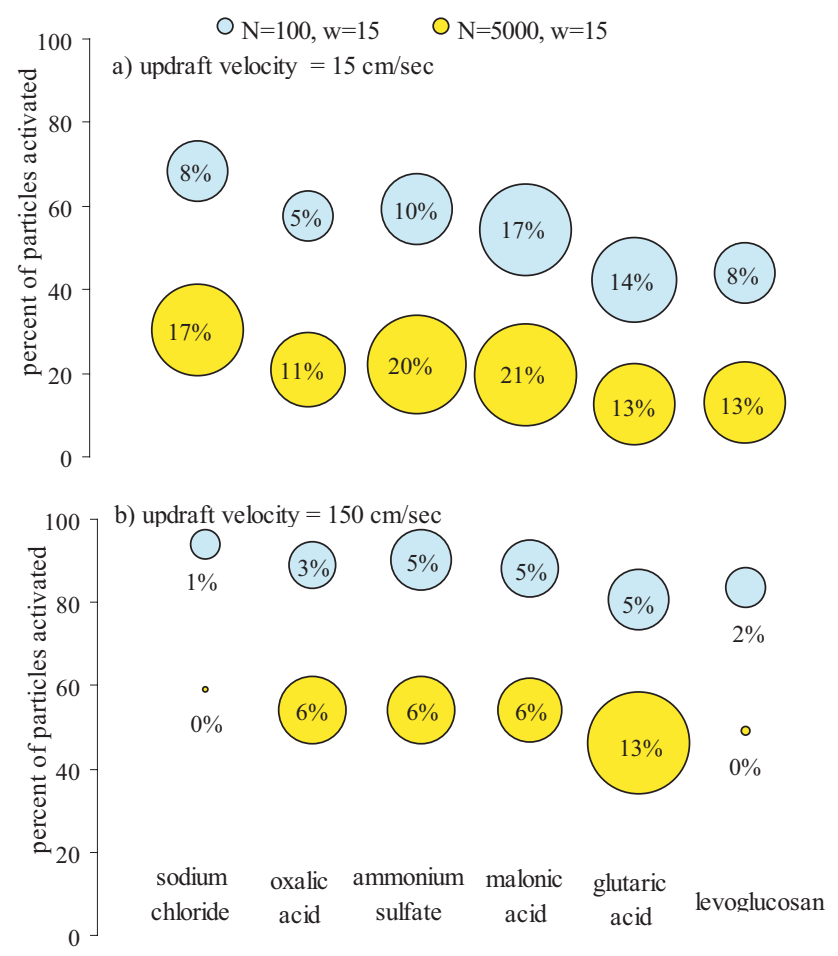

Fig. 13. Parcel model results expressed as percent of activated droplets for each of the species studied: sodium chloride, ammonium sulfate, oxalic acid, malonic acid, glutaric acid and levoglucosan. The percentage shown in each bubble represents the difference between the upper and lower values of the model predictions for the two cases of water activity estimates, as described in the text.

\section{$7 \quad$ Summary and conclusions}

The methodology described in Part I for converting HTDMA-derived water uptake data into water activity as a function of solute wt $\%$ is applied to several atmosphericallyrelevant organic species. Estimates of water activity for aqueous solutions of glutaric, malonic, and oxalic acids are compared with previously-published water activity data and found to be in reasonably good agreement. Estimates of HTDMA-derived water activities for aqueous solutions of levoglucosan are compared with previously-published water activity data for aqueous solutions of levoglucosan and similar sugars, and are also found to be in good agreement. From the comparisons we conclude that glucose and fructose are acceptable surrogates in predicting the water activity and critical dry diameters for levoglucosan aqueous solutions, and presumably for mannosan and galactosan solutions, based on the similar growth factors for those compounds that were reported by Chan et al. (2005). The water activities for the various organic species studied are used here to predict critical dry diameters. The predicted critical dry diameters are in reasonable agreement with previous experimental results, and with other model predictions, within 
typical experimental uncertainty. However, the applicability of this methodology to mixed-composition aerosols has not yet been tested; in multicomponent aerosols, interactions between solutes may produce additional errors.

For each compound studied here, the HTDMA-derived and other published estimates of solution water activities are used to define hygroscopic behavior of particles activated to cloud droplets in an adiabatic parcel model. Of particular interest is the use of the model results to infer whether uncertainties in solution water activities for a particular compound lead to significant $(>15 \%)$ changes in number concentrations of nucleated drops. We also seek to define the magnitude of the compound-to-compound variation in hygroscopic behavior that is required to produce significantly different drop number concentrations. Our results suggest that ammonium sulfate, malonic acid and oxalic acid all have similar activities as CCN, whereas the hygroscopic behaviors of levoglucosan and glutaric acid are sufficiently different to cause significant reductions in number concentrations of activated drops. Further, for the species studied here, the accuracy of the HTDMA-derived solution water activities is sufficient to characterize their cloud nucleating behavior for purposes of estimating aerosol-cloud interactions. From the limited test cases presented here, it is clear that modest changes in hygroscopic behavior have little to no effect on total drop number concentrations (in agreement with the findings of Ervens et al., 2005), and that aerosol number concentrations and updraft velocities have a far greater impact on drop number concentration than the composition of the aerosol, as was also noted by Feingold (2003).

Acknowledgements. This material is based upon work supported by the U.S. National Science Foundation under Grant No.s NSF-ATM-0436196 and NSF-ATM-0071321. This work was also supported in part by the NOAA Office of Global Programs. K. Koehler gratefully acknowledges support from a NASA Graduate Student Research Program Fellowship. We thank C. Chan for providing his data to us, $\mathrm{S}$. Clegg for providing the thermodynamic model outputs, and M. Bilde for her assistance with the evaporation calculations.

Edited by: Y. Rudich

\section{References}

Bhandari, B. and Bareyre, I.: Estimation of crystalline phase present in the glucose crystal-solution mixture by water activity measurement, Lebensmittel-Wissenschaft Und-TechnologieFood Science and Technology, 36 (7), 729-733, 2003.

Bilde, M., Svenningsson, B., Monster, J., and Rosenorn, T.: Evenodd alternation of evaporation rates and vapor pressures of C3C9 dicarboxylic acid aerosols, Env. Sci. \& Tech., 37 (7), 13711378, 2003.

Bilde, M. and Svenningsson, B.: CCN activation of slightly soluble organics: the importance of small amounts of inorganic salt and particle phase, Tellus Series B-Chemical and Physical Meteorology, 56 (2), 128-134, 2004.

Braban, C. F., Carroll, M. F., Styler, S. A., and Abbatt, J. P. D.: Phase transitions of malonic and oxalic acid aerosols, J. Phys. Chem. A, 107 (34), 6594-6602, 2003.

Carrico, C. M., Kreidenweis, S. M., Malm, W. C., Day, D. E., Lee, T., Carrillo, J., McMeeking, G. R., and Collett, J. L.: Hygroscopic growth behavior of a carbon-dominated aerosol in Yosemite National Park, Atmos. Environ., 39 (8), 1393-1404, 2005.

Chan, M. N., Choi, M. Y., Ng, N. L., and Chan, C. K.: Hygroscopicity of water-soluble organic compounds in atmospheric aerosols: Amino acids and biomass burning derived organic species, Environ. Sci. Technol., 39 (6), 1555-1562, 2005.

Chen, C. C., Tao, C. J., and Cheng, H. C.: Condensation of supersaturated water vapor on charged/neutral nanoparticles of glucose and monosodiurn glutamate, J. Colloid Interface Sci., 255 (1), 158-170, 2002.

Clegg, S. L., Brimblecombe, P., and Wexler, A. S.: Thermodynamic model of the system H+-NH4+-Na+-SO42-NB3-ClH2O at 298.15 K, J. Phys. Chem. A, 102 (12), 2155-2171, 1998.

Comesana, J. F., Correa, A., and Sereno, A. M.: Water activity at 35 degrees $\mathrm{C}$ in 'sugar' plus water and 'sugar' plus sodium chloride plus water systems, Int. J. Food Sci. Tech., 36 (6), 655-661, 2001.

Corrigan, C. E. and Novakov, T.: Cloud condensation nucleus activity of organic compounds: a laboratory study, Atmos. Environ., 33 (17), 2661-2668, 1999.

Cruz, C. N. and Pandis, S. N.: A study of the ability of pure secondary organic aerosol to act as cloud condensation nuclei, Atmos. Environ., 31 (15), 2205-2214, 1997.

Davies, M. and Thomas, D.: 1sopiestic Studies of Aqueous. Dicarboxylic Acid Solutions, J. Phys. Chem., 60 (1), 41-44, 1956.

Ervens, B., Feingold, G., Clegg, S. L., and Kreidenweis, S. M.: A modeling study of aqueous production of dicarboxylic acids: 2 . Implications for cloud microphysics, J. Geophys. Res.-Atmos., 109(D15), doi:10.1029/2004JD004575, 2004.

Ervens, B., Feingold, G., and Kreidenweis, S. M.: Influence of water-soluble organic carbon on cloud drop number concentration, J. Geophys. Res., 110, doi:10.1029/2004JD005634, 2005.

Feingold, G.: Modeling of the first indirect effect: Analysis of measurement requirements, Geophys. Res. Lett., 30(19), 1997, doi:10.1029/2003GL017967, 2003.

Feingold, G. and Heymsfield, A. J.: Parameterizations of Condensational Growth of Droplets for Use in General-Circulation Models, J. Atmos. Sci., 49 (23), 2325-2342, 1992.

Ferreira, O., Brignole, E. A., and Macedo, E. A.: Phase equilibria in sugar solutions using the A-UNIFAC model, Ind. Eng. Chem. Res., 42 (24), 6212-6222, 2003.

Fine, P. M., Cass, G. R., and Simoneit, B. R. T.: Organic compounds in biomass smoke from residential wood combustion: Emissions characterization at a continental scale, J. Geophys. Res., 107(D21), 8349, doi:10.1029/2001JD000661, 2002.

Gaman, A. I., Kulmala, M., Vehkamaki, H., Napari, I., Mircea, M., Facchini, M. C., and Laaksonen, A.: Binary homogeneous nucleation in water-succinic acid and water-glutaric acid systems, J. Chem. Phys., 120 (1), 282-291, 2004.

Gerber, H. E., Hoppel, W. A., and Wojciechowski, T. A.: Experimental-Verification of Theoretical Relationship between 
Size and Critical Supersaturation of Salt Nuclei, J. Atmos. Sci., 34 (11), 1836-1841, 1977.

Giebl, H., Berner, A., Reischl, G., Puxbaum, H., Kasper-Giebl, A., and Hitzenberger, R.: CCN activation of oxalic and malonic acid test aerosols with the University of Vienna cloud condensation nucleus counter, J. Aerosol Sci., 33, 1623-1634, 2002.

Hansen, A. R. and Beyer, K. D.: Experimentally determined thermochemical properties of the malonic acid/water system: Implications for atmospheric aerosols, J. Phys. Chem. A, 108 (16), 3457-3466, 2004.

Kawamura, K., Kasukabe, H., and Barrie, L. A.: Source and reaction pathways of dicarboxylic acids, ketoacids and dicarbonyls in arctic aerosols: One year of observations, Atmos. Environ., 30 (10-11), 1709-1722, 1996.

Kreidenweis, S. M., Koehler, K., DeMott, P. J., Prenni, A. J., Carrico, C., and Ervens, B.: Water activity and activation diameters from hygroscopicity data - Part I: Theory and application to inorganic salts, Atmos. Chem. Phys., 5, 1357-1370, 2005.

Kumar, P. P., Broekhuizen, K., and Abbatt, J. P. D.: Organic acids as cloud condensation nuclei: Laboratory studies of highly soluble and insoluble species, Atmos. Chem. Phys., 3, 509-520, 2003.

Lerici, C. R., Piva, M., and Rosa, M. D.: Water Activity and Freezing-Point Depression of Aqueous-Solutions and Liquid Foods, J. Food Sci., 48 (6), 1667-1669, 1983.

Lide, D. R.: CRC Handbook of Chemistry and Physics, CRC Press LLC, Boca Raton, FL, 2000.

Makar, P. A.: The estimation of organic gas vapour pressure, Atmos. Environ., 35 (5), 961-974, 2001.

Mikhailov, E., Vlasenko, S., Niessner, R., and Pöschl, U.: Interaction of aerosol particles composed of protein and salts with water vapor: hygroscopic growth and microstructural rearrangement, Atmos. Chem. Phys., 4, 323-350, 2004.

Miyajima, K., Sawada, M., and Nakagaki, M.: Studies on AqueousSolutions of Saccharides, 1. Activity-Coefficients of Monosaccharides in Aqueous-Solutions at 25-Degrees-C, Bull. Chem. Soc. Jpn., 56 (6), 1620-1623, 1983.

Mochida, M. and Kawamura, K.: Hygroscopic properties of levoglucosan and related organic compounds characteristic to biomass burning aerosol particles, J. Geophys. Res.-Atmos., 109(D21), D21202, doi:10.1029/2004JD004962, 2004.

Parsons, M. T., Mak, J., Lipetz, S. R., and Bertram, A. K.: Deliquescence of malonic, succinic, glutaric, and adipic acid particles, J. Geophys. Res.-Atmos., 109(D6), doi:10.1029/2003JD004075, 2004.

Peng, C., Chan, M. N., and Chan, C. K.: The hygroscopic properties of dicarboxylic and multifunctional acids: Measurements and UNIFAC predictions, Environ. Sci. Technol., 35 (22), 44954501, 2001a.
Peng, C. G., Chow, A. H. L., and Chan, C. K.: Hygroscopic study of glucose, citric acid, and sorbitol using an electrodynamic balance: Comparison with UNIFAC predictions, Aerosol Sci. Technol., 35 (3), 753-758, 2001b.

Prenni, A. J., De Mott, P. J., and Kreidenweis, S. M.: Water uptake of internally mixed particles containing ammonium sulfate and dicarboxylic acids, Atmos. Environ., 37 (30), 4243-4251, 2003.

Prenni, A. J., DeMott, P. J., Kreidenweis, S. M., Sherman, D. E., Russell, L. M., and Ming, Y.: The effects of low molecular weight dicarboxylic acids on cloud formation, J. Phys. Chem. A, 105 (50), 11240-11 248, 2001.

Raymond, T. M. and Pandis, S. N.: Cloud activation of singlecomponent organic aerosol particles, J. Geophys. Res.-Atmos., 107(D24), doi:10.1029/2002JD002159, 2002.

Robinson, R. A. and Stokes, R. H.: Electrolyte Solutions, Butterworths, London, 571 pp., 1959.

Ruegg, M. and Blanc, B.: The Water Activity of Honey and Related Sugar Solutions, Lebensmittel-Wissenschaft \& Technologie, 14 (1), 1-6, 1981.

Saxena, P., Hildemann, L. M., McMurry, P. H., and Seinfeld, J. H.: Organics alter hygroscopic behavior of atmospheric particles, J. Geophys. Res., 100(D9), 18 755-18770, 1995.

Scatchard, G., Hamer, W. J., and Wood, S. E.: Isotonic Solutions, I. The chemical potential of water in aqueous solutions of sodium chloride, potassium chloride, sulfuric acid, sucrose, urea and glycerol at $25^{\circ} \mathrm{C}$, J. Am. Chem. Soc., 60, 3061-3070, 1938.

Shulman, M. L., Jacobson, M. C., Charlson, R. J., Synovec, R. E., and Young, T. E.: Dissolution behavior and surface tension effects of organic compounds in nucleating cloud drops, Geophys. Res. Lett., 23(3), 277-280, 1996.

Simoneit, B. R. T., Schauer, J. J., Nolte, C. G., Oros, D. R., Elias, V. O., Fraser, M. P., Rogge, W. F., and Cass, G. R.: Levoglucosan, a tracer for cellulose in biomass burning and atmospheric particles, Atmos. Environ., 33, 173-182, 1999.

Svenningsson, B., Rissler, J., Swietlicki, E., Mircea, M., Bilde, M., Facchini, M. C., Decesari, S., Fuzzi, S., Zhou, J., Monster, J., and Rosenorn, T.: Hygroscopic growth and critical supersaturations for mixed aerosol particles of inorganic and organic compounds of atmospheric relevance, Atmos. Chem. Phys. Discuss., 5, 2833-2877, 2005.

Tuckermann, R. and Cammenga, H. K.: The surface tension of aqueous solutions of some atmospheric water-soluble organic compounds, Atmos. Environ., 38 (36), 6135-6138, 2004.

Wise, M. E., Surratt, J. D., Curtis, D. B., Shilling, J. E., and Tolbert, M. A.: Hygroscopic growth of ammonium sulfate/dicarboxylic acids, J. Geophys. Res.-Atmos., 108(D20), doi:10.1029/2003JD003775, 2003. 